6. Механические свойства сталей и сплавов при не стационарном нагружении: справочник / Д.А. Гохфельд [и др.]. - Екатеринбург: УрО РАН, 1996.

7. Тарнопольский Ю.М., Скудра А.М. Конструкционная прочность и деформативность стеклопластиков. - Рига, 1966. - 260 с.

8. Трощенко В.Т., Сосновский Л.А. Сопротивление усталости металлов и сплавов: справочник. Ч. 1. Киев: Наук, думка, 1987.

9. Фудзии Т., Дзако М. Механика разрушения композиционных материалов. - М.: Мир, 1982. - 232 с.

10. Черепанов Г.П. Механика разрушения композиционных материалов. - М.: Наука, 1983. - 296 с.

Лебедев Игорь Константинович, канд. техн. наук, ООО «Системы армированных фильтров и трубопроводов» («САФИТ»). Россия.
Мороз Николай Григорьевич, канд. техн. наук, ООО «Системы армированных фильтров и трубопроводов» («САФИТ»). Россия.

141351, Московская обл., Сергиево-Посадский $p$-н, д. Жучки, $2 \partial$.

Тел.: (495) 989-48-42.

Калинников Александр Николаевич, зав. лабораторией, Межотраслевой инжиниринговый центр «Композить России» МГТУ им. Н.Э. Баумана, ФГАОУ ВО «Московский государственный технический университет имени Н.Э. Баумана (национальный исследовательский университет)». Россия.

105005, г. Москва, ул. 2-я Бауманская, 5.

Тел.: (499) 263-63-91.

Ключевые слова: баллоны высокого давления; стеклопластиковая оболочка; высокопрочный углепластик; малоцикловая прочность; коррозионная усталость.

\title{
ON AN ALGORITHM FOR DESIGNING MULTILAYER METAL COMPOSITE PRESSURE CYLINDERS WITH A THIN-WALLED LINER
}

Lebedev Igor Konstantinovich, Candidate of Technical Sciences, JSC "Reinforced Filters and Pipelines Systems" (SAFIT). Russia.

Moroz Nikolai Grygoryevich, Candidate of Technical Sciences, JSC "Reinforced Filters and Pipelines Systems" (SAFIT). Russia.

Kalinnikov Alexander Nikolayevich, Head of laboratory, Intersectoral Engineering Center "Composites of Russia”, Bauman Moscow State Technical University. Russia.

Keywords: high-pressure bottles; glass-reinforced plastic shell; high-strength carbon-fiber-reinforced plastic; low-cycle strength; corrosive fatigue.
It is regarded the formulation of the problem of rational design of metal-composite pressure cylinder, involving the determination of the shape of the cylinder forming, which provides an acceptable level of deformability of the liner at a given service life of the cylinder. It is shown that for the final selected reinforcement scheme the method of step loading is used with the determination of the stress and strain arising in the materials of construction, when it is loaded to the level of the test pressure.

\section{ПРОБЛЕМЫ БЕЗОПАСНОСТИ НА ПОДЗЕМНОМ ТРУБОПРОВОДНОМ ТРАНСПОРТЕ И ТЕОРЕТИЧЕСКОЕ ОБОСНОВАНИЕ ИХ УСТРАНЕНИЙ}

Удк 658.382

университет

ОРЛОВ Павел Сергеевич, Ярославская государственная сельскохозяйственная академия

СОЦКАЯ Ирина Марковна, Ярославская государственная сельскохозяйственная академия

ПОПОВА Екатерина Сергеевна, Ярославская государственная сельскохозяйственная академия

ШКРАБАК Роман Владимирович, Санкт-Петербургский государственный аграрный

университет

Приведены результаты исследований по проблемам безопасности на подземном трубопроводном транспорте. Показано, ито основными причинами, снижающими безопасность использования подземного трубопроводного транспорта, являются износ магистральных трубопроводов и оборудования, а также коррозионные процессы. Разработаны технические решения для повышения надежности трубопроводно20 транспорта, его безопасности.

Введение. В России широко развита сеть подземного трубопроводного транспорта (водо- и теплопроводы, нефтепроводы, канализационные системы, газопроводы). Каждый из этих видов имеет свои особенности и характеризуется своими показателями опасности и вредности. В связи с этим генерируются профессиональные риски, связанные с тем, что на территории Российской Федерации функционирует более 3700 опасных производственных объектов нефтегазовых предприятий газоперекачивающих объ- ектов - компрессорных станций (КС) [6].

Почти половина всех магистральных газопроводов диаметром более 700 мм находится за Полярным кругом на территориях, на которых осуществляется только выпас оленей (Республика Коми - менее 1 чел. $/$ км$\left.^{2}\right)$. Южнее плотность сельского населения растет, и в Вологодской области составляет 1-5 чел./км²; в Костромской, Новгородской, Тверской и Ярославской областях 5-10 чел./км²; во Владимирской, Ивановской, Кировской, Ленинградской, Мос- 
ковской и Нижегородской областях - 10-25 чел./км², что значительно увеличивает опасность для населения, учитывая, что на расстоянии до 500 м от трасс газопроводов в Вологодской области расположено 64 населенных пункта с численностью населения до 500 жителей в каждом и 3 города, во Владимирской области - 38 населенных пунктов и 2 города, в Ивановской области - 23 населенных пункта и 1 город, в Костромской области - 12 населенных пунктов и 2 города, в Ярославской области - 43 населенных пункта и 2 города. Во всех перечисленных областях, кроме Ивановской и Костромской, магистральные газопроводы проложены в три - четыре нитки.

В Вологодской области общая протяженность магистральных газопроводных трасс составляет 725 км, во Владимирской области - 240 км, в Костромской - 52 км, в Ивановской области 163 км, в Ярославской - 371 км.

Газопроводы прокладывают в малонаселенных районах, тем не менее, на территории Владимирской, Вологодской, Ивановской, Костромской и Ярославской областей вблизи районов интенсивной хозяйственной деятельности (населенные пункты, пересечение дорог и судоходных водных преград) проложено 350 км газопроводов; по территории, на которой осуществляется регулярная хозяйственная деятельность сельского населения (пахотные земли), проложено 279 км газопроводов; по территории, на которой осуществляется спорадическая хозяйственная деятельность (леса) проходит 877 км трасс газопроводов. Даже незначительная авария на газопроводе, приводит к утечке больших количеств легковоспламеняющегося метана, так как от момента разрыва трубопровода до момента прекращения поступления газа к месту разрыва в самом благоприятном случае проходит несколько часов пока будет отсечен аварийный участок запорными устройствами по обе стороны от места разрыва [2].

Возгорание газа - это прямые материальные потери метана, а аварии в лесных массивах и сельскохозяйственных угодьях приводят к выгоранию леса и посевов не менее чем на 25 га [3].

Наибольшую опасность подземные газопроводы представляют именно для сельского населения, проживающего и повседневно осуществляющего хозяйственную деятельность вблизи трасс магистральных газопроводов.

Методика исследований. В работе анализировали проблемы безопасности на подземном трубопроводном транспорте и их причины.

Результаты исследований. Более трети аварий за 2012-2014 гг. произошло на газопроводах с износом основных фондов выше $85 \%$, а 60 \% материального ущерба приходится на аварийные трубопроводы с износом более 50 \% (табл. 1) [1].

Значительное влияние на возможность возникновения аварийных ситуаций на КС - оказывает большое число элементов, затрудняющих строительно-монтажные работы (врезки, переходники, арматура), выступая концентраторами снижения качества контроля. Наличие выходов подземного газопровода на дневную поверхность обусловливает дополнительные напряжения в теле труб и вызывает коррозионную активность металла, приводящую к авариям на взрывопожароопасных объектах из-за свойств перекачиваемой среды - метана, находящегося под высоким давлением.

По статистике Ростехнадзора, основными причинами возникновения аварий выступают дефекты строительно-монтажных работ и оборудования и коррозионные процессы, в том числе межкристаллитная коррозия. Риск аварий на КС зависит в основном от технического состояния технологических трубопроводов, а их качественная диагностика играет важную роль в обеспечении промышленной безопасности и эксплуатационной надежности. Наиболее опасны дефекты коррозионного растрескивания под напряжением (КРН). Существенный вклад в их образование вносят технологии производства труб, нарушения при строительстве газопровода и условия его эксплуатации, развивающиеся в процессе функционирования объекта и определяемые внешними условиями, включая пожары (табл. 2).

Рост дефектов КРН прослеживается на протяжении 10 лет после ввода в эксплуатацию для всех основных диаметров магистральных газопроводов кроме трубопроводов условным диаметром 720 мм (табл. 3) [4].

Существующий уровень пожаро-взрывоопасности обусловливает потенциальную опасность возникновения аварий на подземных магистральных трубопроводах, 70 \% которых связано с КРН [1].

Одним из наиболее опасных повреждений конструкций газифицированных объектов АПК, работающих в условиях действия значительных растягивающих нагрузок (в том числе и при повышенных температурах), является межкристаллитная коррозия. Результатом ее являются разрушения в зоне сварных швов подземных трубопроводов и поверхностей нагрева паровых котлов, что может привести к травматизму обслуживающего персонала. Чаще всего межкристаллитная коррозия наблюдается в зоне термического влияния сварных швов и в наплавленном металле сварного

Таблица 1

Аварийность на магистральном трубопроводном транспорте

\begin{tabular}{|c|c|c|c|c|}
\hline \multirow{2}{*}{ Год } & \multicolumn{4}{|c|}{ Аварийность на магистральном трубопроводном транспорте } \\
\cline { 2 - 6 } & Число аварий & $\begin{array}{c}\text { Длина трубопровода, } \\
\text { тыс. км }\end{array}$ & $\begin{array}{c}\text { Грузооборот, млрд т·км } \\
\text { млн руб. }\end{array}$ & $\begin{array}{c}\text { Ущерб от аварий, } \\
\text { Число погибших }\end{array}$ \\
\hline 2009 & 28 & 231,0 & 2246 & 371,0 \\
\hline 2010 & 13 & 232,6 & 2382 & 146,0 \\
\hline 2011 & 17 & 237,5 & 2422 & 161,5 \\
\hline 2012 & 21 & 245,2 & 2553 & 154,8 \\
\hline 2013 & 12 & 245,8 & 1513 & 318,9 \\
\hline 2014 & 8 & 248,1 & 2423 & 96,59 \\
\hline
\end{tabular}




\section{Пожары в РФ}

\begin{tabular}{|c|c|c|c|c|c|c|}
\hline \multirow{2}{*}{ Объект } & \multicolumn{3}{|c|}{2013 г. } & \multicolumn{3}{|c|}{2014 г. } \\
\hline & Пожары & Гибель & Травмы & Пожары & Гибель & Травмы \\
\hline Производственное здание & 3137 & 95 & 166 & 3099 & 113 & 185 \\
\hline Склад & 1422 & 21 & 57 & 21395 & 14 & 27 \\
\hline Площадка хранения, сельхозугодья & 3443 & 8 & 33 & 3512 & 10 & 43 \\
\hline Жилое здание, надворная постройка & 104592 & 9670 & 8061 & 103579 & 9339 & 8067 \\
\hline Одноквартирный дом & 28622 & 5125 & 2358 & 29371 & 4997 & 2374 \\
\hline Многоквартирный дом & 30245 & 3119 & 4489 & 28353 & 2872 & 4390 \\
\hline С.-х.здание & 694 & 22 & 17 & 617 & 14 & 7 \\
\hline Стройка & 978 & 63 & 90 & 927 & 57 & 97 \\
\hline Промышленная установка & 1098 & 63 & 90 & 927 & 57 & 97 \\
\hline Транспорт & 23434 & 158 & 455 & 22847 & 123 & 399 \\
\hline Предприятие торговли & 3599 & 18 & 49 & 3235 & 16 & 50 \\
\hline Учебное заведение & 270 & 4 & 7 & 228 & 1 & 3 \\
\hline Лечебное здание & 192 & 83 & 18 & 169 & 9 & 8 \\
\hline Сервисное обслуживание & 1057 & 7 & 27 & 1090 & 7 & 26 \\
\hline Администрация & 938 & 14 & 22 & 880 & 20 & 37 \\
\hline Культурно-досуговое здание & 305 & 1 & 9 & 266 & 1 & 11 \\
\hline Здание временного пребывания людей & 258 & 20 & 29 & 211 & 15 & 27 \\
\hline Прочие объекты & 8049 & 390 & 2036 & 7773 & 370 & 1961 \\
\hline
\end{tabular}

Таблица 3

Тенденция роста числа дефектов КРН

\begin{tabular}{|c|c|c|c|c|c|c|c|c|c|c|}
\hline \multirow{2}{*}{$D_{\mathrm{y}}$, MM } & \multicolumn{10}{|c|}{ Год } \\
\hline & 2004 & 2005 & 2006 & 2007 & 2008 & 2009 & 2010 & 2011 & 2012 & 2013 \\
\hline 1020 & 0 & 0 & 20 & 120 & 150 & 190 & 280 & 380 & 1100 & 1400 \\
\hline 1420 & 0 & 0 & 5 & 4 & 80 & 120 & 189 & 220 & 750 & 1190 \\
\hline 1220 & 0 & 0 & 0 & 0 & 0 & 3 & 6 & 80 & 140 & 200 \\
\hline 720 & 0 & 0 & 0 & 0 & 0 & 0 & 0 & 0 & 0 & 4 \\
\hline
\end{tabular}

шва [8] - в тех местах конструкции, где шел интенсивный рост кристаллов. Основная задача, стоящая в настоящее время перед предприятиями АПК и организациями, эксплуатирующими опасные производственные объекты коммунального хозяйства, - снижение аварийности подземных трубопроводов, так как эксплуатируемые подземные водоводы и газопроводы в большинстве своем давно выработали ресурс, а замена их требует значительных капитальных вложений.

Вследствие межкристаллитной коррозии происходит от 5 до 10 \% аварий на трубопроводах.

Существующие гипотезы протекания коррозионных процессов объясняют механизм коррозии у легированных и высокоуглеродистых сталей. Вместе с тем существующие теории не объясняют причин возникновения межкристаллитной коррозии у сталей без легирующих добавок, например, у стали 20, широко применяющейся не только в энергокотлостроении, но и для изготовления труб газопроводов.

Основной причиной возникновения электрохимических процессов именно по границам зерен кристаллов следует считать наводороживание металла, возникающее при наличии значительных знакопеременных нагрузок. Насыщение металла водородом приводит к разблагороживанию электродного потенциала и возникновению гальванических элементов дифференциальной наводороженности [2]. Источником водорода чаще всего выступает вода, взаимодействуя с железом по реакции

$$
\mathrm{Fe}+\mathrm{H}_{2} \mathrm{O}=\mathrm{FeO}+2 \mathrm{H} \uparrow
$$

Реакция обратима и до 870 К сдвинута вправо. В результате взаимодействия железа с водой выделяется атомарный водород, который либо рекомбинирует, превращаясь в молекулы водорода Н2个, либо адсорбируется поверхностью металла. В растворах щелочей железо взаимодействует с водой также с образованием водорода:

$$
\mathrm{Fe}+2 \mathrm{H}_{2} \mathrm{O}=\mathrm{Fe}(\mathrm{OH})_{2}+2 \mathrm{H} \uparrow .
$$

При нагревании железо реагирует с концентрированными (примерно 50 \%) растворами гидрооксидов щелочных металлов с выделением атомарного водорода [7]:

$$
\mathrm{Fe}+2(\mathrm{OH})_{1}-+2 \mathrm{H}_{2} \mathrm{O}=\left[\mathrm{Fe}(\mathrm{OH})_{4}\right]_{2}-+2 \mathrm{H} \uparrow
$$

Способствуют наводороживанию сварных швов и околошовной зоны термические процессы, происходящие при сварке металла, во время которых происходит укрупнение зерна в зоне перегрева и рост кристаллов - столбчатых дендритов в центре сварного шва, так как стенки шва интенсивно отводят тепло из сварочной ванны [1].

Из-за малых размеров входных отверстий в межкристаллитные полости атомы других элементов проникнуть не могут, так как радиусы двух наиболее распространенных и наиболее часто встречающихся в атмосфере атомов газов - азота и кислорода - больше атома водорода в 1,476 и в 1,629 раза соответственно [4].

В результате наводороживания стенки межкристаллитных, межблочных и межфрагментарных объемов покрываются моноатомным слоем водорода, единственный электрон которого в металле становится квазиколлективизированным. Абсорбированный поверхностью металла водород связан с атомами металла абсорбционными связями, а водород с единственным электроном, покрывающий тончайшим атомарным слоем поверхность стали, вследствие контактной разности потенциалов оказывается «заряженным» положительно (получает эффективный положительный «заряд» $\left.q \cdot Z^{*}\right)$. 
Атомы водорода, в соответствии с законом Фика, «заколачиваются» в межкристаллитные, межфрагментарные и межблочные пространства (в которых при нормальных условиях сохраняется глубокий вакуум) атмосферным давлением, и исходя из условий нагружения создают высокие давления на стенки полостей, а значит, и стенки полостей также оказывают на атомы водорода такое же давление. Наводороживание большинства углеродистых и нержавеющих сталей существенно разблагороживает их электродные потенциалы при контакте последних с электролитом [12], вследствие образования концентрационного водородного гальванического элемента, расходным материалом которого служит водород, находящийся под огромным давлением в межкристаллитных пространствах. В результате разблагороживания части металлической поверхности устья микрообъема, контактирующего с электролитом, появляется электрическая цепь с двумя стальными электродами, один из которых имеет потенциал на несколько десятых долей вольта ниже другого и возникает гальванический элемент дифференциальной наводороженности. Плотность тока коррозии может достигать $32,7 \mathrm{~A} / \mathrm{M}^{2}$, что теоретически соответствует скорости коррозии 37,9 мм/год. Окисляющимся электродом (анодом) подобного гальванического элемента является устье межкристаллитного объема интенсивно разрушающееся электрохимической коррозией. Основная токообразующая реакция анода - окисление водорода:

$$
0,5 \mathrm{H}_{2}=\mathrm{H}_{1}++\mathrm{e}, \text { ЕР- }=-0,00 \mathrm{~B}(\text { анод). }
$$

Катодом служат дневные, не наводороженные поверхности металла: катодный процесс представлен восстановлением водорода:

$$
\mathrm{H}_{1}++\mathrm{e}=0,5 \mathrm{H}_{2}, E \mathrm{P}+=0,00 \text { В (катод). }
$$

ЭДС этого гальванического элемента дифференциальной наводороженности может достигать $0,25 \mathrm{~B}$, а с учетом адсорбционной составляющей (кратковременно) анодный потенциал может понижаться, по отношению к катоду, до $-0,4$ В. При понижении анодного потенциала ниже $-0,12$ В становится возможным протекание анодной токообразующей реакции окисления гидрооксида железа II до метагидрооксида железа III:

$$
\mathrm{Fe}(\mathrm{OH})_{2}+(\mathrm{OH})_{1}-\rightarrow \mathrm{FeO}(\mathrm{OH})+\mathrm{H}-\mathrm{O}+\mathrm{e} ;
$$

потенциал которой в соответствии с диаграммой Пурбе может принмать значения от $-0,12$ В и ниже (в зависимости от $\mathrm{pH}$ среды).

В увеличенное коррозией входное сечение межкристаллитного объема проникают другие атомы и молекулы, в том числе молекулы $\mathrm{O}_{2}, \mathrm{H}_{2} \mathrm{O}$, тогда возможны следующие реакции:

$4 \mathrm{Fe}+2 \mathrm{H}_{2} \mathrm{O}+3 \mathrm{O}_{2}=4 \mathrm{FeO}(\mathrm{OH})=2\left(\mathrm{Fe}_{2} \mathrm{O} 3 \cdot \mathrm{H}_{2} \mathrm{O}\right),(4)$

$$
\begin{aligned}
& 4 \mathrm{Fe}(\mathrm{OH})_{2}+\mathrm{O}_{2}=4 \mathrm{FeO}(\mathrm{OH})+2 \mathrm{H}_{2} \mathrm{O}, \\
& 4 \mathrm{Fe}(\mathrm{OH})_{2}+2 \mathrm{H}_{2} \mathrm{O}+\mathrm{O}_{2}=4 \mathrm{Fe}(\mathrm{OH})_{3} .
\end{aligned}
$$

Любая, идущая с выделением водорода реакция $(1,2,3)$, обеспечивает сколь угодно долгое протекание токообразующих процессов, понижающих анодный потенциал устья межкристаллитного объема и сдвигает любую из реакций $(4,5,6)$ коррозионного процесса вправо.

Для понимания основных причин возникновения межкристаллитной коррозии необходимо напомнить, что Ф. Тодт, ссылаясь на Кистяковского отмечал, что стальной электрод, начиная с потенциала $\varphi=-0,480$ В н.в.э. $(-0,780$ В м.с.э.) и ниже, ведет себя как водородный электрод [10]. В Академии наук СССР были проведены измерения диэлектрических свойств двойного электрического слоя у поверхности стали в водных электролитах, которые выявили, что при потенциале $\varphi=-0,4808$ В н.в.э. стальная поверхность полностью очищается от адсорбированного на ней кислорода [5]. Аналогия в поведении водородного и стального электродов при потенциале $\varphi \leq-0,480$ В н.в.э. означает, что в этих условиях полностью исключается протекание реакции:

$$
\mathrm{O}_{2}+2 \mathrm{H}_{2} \mathrm{O}+4 \mathrm{e}=\mathrm{OH}^{1-} \text {, }
$$

а остаточная скорость коррозионного окисления стали, при ее катодной поляризации обеспечивается только водородным окислением или водородной деполяризацией:

$$
\mathrm{H}^{1+}+\mathrm{e} \rightarrow \mathrm{H}
$$

Рассмотрим цепочку потенциалов анодных реакций, проявляющихся при окислении атомов железа с образованием ими гидроокисей железа:

$$
\begin{aligned}
& \mathrm{Fe} \rightarrow \mathrm{FeOH} \rightarrow \quad \mathrm{Fe}(\mathrm{OH})_{2} \rightarrow \mathrm{Fe}(\mathrm{OH})_{3} \\
& -0,440 \mathrm{~B}-0,760 \mathrm{~B}-0,120 \mathrm{~B}-0,560 \mathrm{~B}
\end{aligned}
$$

Потенциалы даны по шкале нормального водородного электрода (н.в.э.).

Для проверки правильности определения потенциала реакций (8)

$$
\mathrm{Fe} \rightarrow \mathrm{FeOH} \text { и } \mathrm{FeOH} \rightarrow \mathrm{Fe}(\mathrm{OH})_{2}
$$

подставим их значения в равенство

$$
(-0,760-0,120) / 2=-0,44 \mathrm{~B},
$$

из которого определяется потенциал реакции $\mathrm{Fe} \rightarrow$ $\mathrm{Fe}_{2}+$, расчетное значение которого совпадает с табличным значением. В общем случае:

$\mathrm{EZ}_{0}=\left(\mathrm{EZ}_{1}+\mathrm{EZ}_{2}\right) / \mathrm{Z}_{2} ; \mathrm{EZ}_{0}=\left(\mathrm{EZ}_{1}+\mathrm{EZ}_{3}\right) / \mathrm{Z}_{3}$,

откуда вычислим $\mathrm{EZ}_{1}, \mathrm{EZ}_{2}, \mathrm{EZ}_{3}$,

где $\mathrm{EZ}_{i}$ - потенциал элемента со степенью окисления $\mathrm{Z}_{i}$. 
Приравняв правые части уравнений, после преобразований получим:

$$
\begin{gathered}
\mathrm{EZ}_{1}=\mathrm{Z}_{2} \mathrm{EZ}_{3}+\mathrm{Z}_{3} \mathrm{EZ}_{2} ; \\
\mathrm{EZ}_{2}=\left(\mathrm{Z}_{2} \mathrm{EZ}_{3}+\mathrm{EZ}_{1}\right) / \mathrm{Z}_{3} ; \mathrm{EZ}_{3}=\left(\mathrm{EZ}_{1}+\mathrm{Z}_{3} \mathrm{EZ}_{2}\right) / \mathrm{Z}_{2} .
\end{gathered}
$$

Продукт первой фазы окисления железа $\mathrm{FeOH}$ неустойчив и способен активно восстанавливаться до железа, $\mathrm{FeOH} \rightarrow \mathrm{Fe}$.

Учитывая эту особенность окисления железа, замедлив образование второй фазы окисления $\mathrm{FeOH} \rightarrow \mathrm{Fe}(\mathrm{OH})_{2}$, можно резко замедлить скорость окисления всей цепочки.

Наложение на сталь потенциала минимальной защиты (практически совпадает с потенциалом реакции $\mathrm{Fe}(\mathrm{OH})_{2} \rightarrow \mathrm{Fe}(\mathrm{OH})_{3}$, равным $-0,560$ В. Это совпадение не случайно, так как равенство минимального защитного потенциала и потенциала реакции образования гидрооксида $\mathrm{Fe}(\mathrm{OH})_{2}$ железа из $\mathrm{FeOH}$ обеспечивает энергетическую устойчивость прикатодного слоя, а выполнение условия $|-0,120|<|-0,560|$ В обеспечивает резкое замедление скорости протекания реакции $\mathrm{FeOH} \rightarrow \mathrm{Fe}(\mathrm{OH})_{2}$ при адекватном ускорении процесса восстановления железа $\mathrm{FeOH} \rightarrow \mathrm{Fe}$.

Для иллюстрации первого положения рассмотрим устойчивость молекул воды во внешнем электрическом поле на катоде внешнего источника (на газопроводе) молекулы воды диссоциируют, если выполняется условие:

$$
\varphi \leq-0,059 \mathrm{pH},
$$

где $\varphi$ - поляризационный потенциал трубопровода (н.в.э.); $\mathrm{pH}$ - величина $\mathrm{pH}$ прикатодного слоя.

Подставляя вместо ф потенциал $-0,560$ В из цепочки (8), найдем $\mathrm{pH}=9,5$. Это же значение рН является равновесным для гидроокиси железа [12]. При минимальном защитном потенциале в прикатодном слое, образованном у поверхности стали, устанавливается энергетическое равновесие между ионами ОН2- соединения $\mathrm{Fe}(\mathrm{OH})_{3}$ и ионами $\mathrm{OH} 2-$ электролита. Это равновесие обеспечивает стабилизацию системы сталь-электролит во времени при наложении на сталь потенциала минимальной защиты $-0,850 \div-0,860$ В м.с.э.

При наложении на сталь защитного потенциала $-1,060$ В м.с.э. рН прикатодного слоя составляет 12,88. При этом устанавливается энергетическое равновесие между ионами $\mathrm{OH}_{2}-$, входящими в состав $\mathrm{FeOH}$, и ионами $\mathrm{OH}_{2}-$ прикатодного слоя. Прикатодный слой становится энергетически устойчивым и даже тогда, когда наложенный на сталь потенциал отличается от величины $-0,760$ В, но система сталь - электролит все же стремится к этой величине.

Коррозионное поведение стали при поляризационном потенциале $\varphi=-0,760$ В н.в.э. можно было бы считать оптимальным так как остаточная скорость ее коррозионного разрушения не превышает 23 \%. Но прекращение прямого электрохимического окисления служит причиной дальнейшего, еще бо- лее опасного, разрушения кристаллической структуры стали.

Так как основной причиной возникновения электрохимических процессов именно по границам зерен кристаллов является наводороживание металла, возникающее при наличии значительных знакопеременных нагрузок, то насыщение металла водородом приводит к разблагороживанию электродного потенциала и возникновению гальванических элементов дифференциальной наводороженности [12].

При потенциале $-0,760$ В н.в.э. молекулы воды у поверхности стали продолжают активно диссоциировать по схеме:

$$
\mathrm{H}_{2} \mathrm{O} \rightarrow \mathrm{OH}_{2}-+\mathrm{H}_{1}+
$$

Образовавшиеся при диссоциации протоны $\left(\mathrm{H}_{1}+\right)$ разряжаются у поверхности стали, образуя атомы $\mathrm{H}$ :

$$
\mathrm{H}_{1}++\mathrm{e} \rightarrow \mathrm{H} \uparrow
$$

Далее атомы $\mathrm{H}$ должны образовывать молекулу $\mathrm{H}_{2}$, но это происходит только при больших плотностях тока защиты, когда оголенные площади поверхнос-

ти трубопровода сравнительно невелики [12].

Источником водорода при отсутствии катодной защиты, а также в промежутках между защитными импульсами выступает вода, взаимодействуя с железом по реакции

$$
\mathrm{Fe}+2 \mathrm{H}_{2}+=\mathrm{Fe}_{2}++2 \mathrm{H} \uparrow
$$

Реакция обратима и до 870 К сдвинута вправо.

В результате взаимодействия железа с водой выделяется атомарный водород, который либо рекомбинирует, превращаясь в молекулы водорода $\mathrm{H}_{2}$, либо адсорбируется поверхностью металла. В растворах щелочей железо взаимодействует с водой также с образованием водорода.

Рекомбинация атомарного водорода затруднена именно ввиду его малых количеств. Способствуют наводороживанию сварных швов и околошовной зоны термические процессы, происходящие при сварке металла, во время которых происходит укрупнение зерна в зоне перегрева и рост кристаллов - столбчатых дендритов в центре сварного шва, так как стенки шва интенсивно отводят тепло из сварочной ванны [9].

ЭДС гальванической пары независимо от концентрации реагирующих компонентов описывается уравнением Нернста:

$$
E=\varphi \mathrm{j} Э--0,0592\{\Delta \mathrm{DpH}+[\lg (c 2 / c 1)] / \mathrm{z}\} .
$$

Приведенное уравнение не учитывает ЭДС адсорбционного концентрационного гальванического элемента, так как время его действия не превышает нескольких секунд. Отношение концентраций в уравнении может быть заменено отношением давлений или отношением парциальных давлений. Понижение потенциала поверхности трубы сдвига- 
ет все окислительные процессы вправо и способствует протеканию межкристаллитной коррозии.

Так как межкристаллитные полости при небольших поперечных сечениях имеют значительную протяженность в толще металла, то возникший концентрационный гальванический элемент дифференциальной наводороженности продолжает свое разрушающее действие, интенсивно расширяя и углубляя межкристаллитную полость. Все это способствует наводороживанию межкристаллитных пространств, резкому понижению их потенциалов и протеканию межкристаллитной коррозии.

Заключение. Повысить безопасность систем трубопроводного транспорта можно путем разработки и внедрения новых технических решений повышения надежности трубопроводного транспорта, способных повысить безопасность эксплуатации магистральных трубопроводов. Авторами разработан способ определения местоположения и глубины межкрсталлитной коррозии и коррозионных повреждений наружных поверхностей подземных и подводных трубопроводов путем катодной поляризации трубопровода, измерения его потенциала и нахождения местоположения и размеров дефектов по изменению поляризационного потенциала без отключения станции катодной защиты позволяющий определять коррозионные повреждения в самом начале их возникновения, что позволяет своевременно принимать эффективные меры по предотвращению коррозионных процессов.

\section{СПИСОК ЛИТЕРАТУРЫ}

1. Абрахимов Ю.Р., Закирова З.А., Башенов А.А. Снижение аварийности на объектах трубопроводного транспорта за счет внедрения современных методов внутритрубной диагностики // Безопасность труда в промышленности. - 2018 - № 2. - С.43-45.

2. Голдобина Л.А., Шкрабак В.С., Орлов П.С. Предупреждение аварий и катастроф на катоднозащищенных подземных трубопроводах бесконтактными методами идентификации коррозионного разрушения. - СПб.; Ярославль, 2012. - 202 с.

3. Елагин А., Ефремов А., Селиванов А. Профессиональные и пожарные риски: найти точки соприкосновения // Охрана труда и социальное страхование. - 2015. - № 12. - С. 69-75.
4. Краткий справочник физико-химических величин / под ред. К.П. Мищенко, А.А. Равделя. - Л.: Химия, 1967. - 184 с.

5. Кучинская Е.М., Веселовская Е.В. Перенапряжение водорода на железном электроде в щелочном растворе в зависимости от состояния его поверхности // Труды 4-го совещания по электрохимии. - М.: АН СССР, 1959. C. $49-57$.

6. Повышение эффективности эксплуатации энергопривода компрессорных станций / Б.П. Поршаков [и др.]. - М., 1992. - 207 с.

7. Погодин В.П., Богоявленский В.Л., Сентюрев В.П. Межкристаллитная коррозия и коррозионное растрескивание нержавеющих сталей в водных средах. - М.: Атомиздат, 1979. - 422 с.

8. Структура и коррозия металлов и сплавов / под ред. Е.А. Ульянина. - М.: Металлургия, 1989. - 400 с.

9. Теория сварочных процессов / под ред. В.В. Фролова. - М.: Высш. шк., 1988. - 559 с.

10. Тодm Ф. Коррозия и защита от коррозии. - М.: Недра, 1978. - 710 с.

11. Хренов К. К. Сварка, резка и пайка металлов. М.: Машиностроение, 1975. - 408 с.

12. Элемент дифференциальной наводороженности / Л.Н. Петров [и др.] // Защита металлов. 1990. - № 2. - С. 296-299.

Шкрабак Владимир Степанович, д-р техн. наук, проф. кафедры «Безопасность технологических процессов и производств», Санкт-Петербургский государственный аграрный университет. Росссия.

196605, Санкт-Петербург - Пушкин, Петербургское mocce, 2.

Тел.: (812) 451-76-18.

Орлов Павел Сергеевич, $\partial-p$. техн. наук, доцент, зав. кафедрой «Электрификациия, Ярославская государственная сельскохозяйственная академия. Россия.

Соцкая Ирина Марковна, канд. техн. наук, доцент, зав. кафедрой «Технический сервис», Ярославская государственная сельскохозяйственная академия. Россия.

Попова Екатерина Сергеевна, инженер кафедры «Механизация сельскохозяйственного производства». Ярославская государственная сельскохозяйственная академия. Россия.

150042, г. Ярославль, Тутаевское шоссе, д. 58.

Тел.: 89159774697.

Шкрабак Роман Владимирович, канд. техн. наук, доцент, Санкт-Петербургский государственный аграрный университет. Россия.

196605, Санкт-Петербург - Пушкин, Петербургское шоссе, 2.

Тел.: (812) 451-76-18.

Ключевые слова: безопасность; трубопроводный транспорт; коррозионные разрушения; взрывы; аварии.

\section{SECURITY PROBLEMS IN UNDERGROUND PIPELINE TRANSPORT AND THEORETICAL SUBSTANTIATION OF THEIR PROTECTION}

Shkrabak Vladimir Stepanovich, Doctor of Technical Sciences, Professor of the chair "Safety of Technological Processes and Productions", St. Petersburg State Agrarian University. Russia.

Orlov Pavel Sergeevich, Doctor of Technical Sciences, Associate Professor, Head of the chair "Electrification", Yaroslavl State Agricultural Academy. Russia.

Sotskaya Irina Markovna, Candidate of Technical Sciences, Associate Professor, Head of the chair "Technical Service", Yaroslavl State Agricultural Academy. Russia.

Popova Ekaterina Sergeevna, Engineer of the chair "Mechanization of Agricultural Production", Yaroslavl State Agricultural Academy. Russia.
Shkrabak Roman Vladimirovich, Candidate of Technical Sciences, Associate Professor, St. Petersburg State Agrarian University. Russia.

Keywords: safety; pipeline transport; corrosion destruction; explosions; accidents.

The results of research on safety problems in underground pipeline transport are presented. It is shown that wear of main pipelines and equipment, as well as corrosion processes, are the main reasons that reduce the safety of using underground pipeline transport. Technical solutions have been developed to improve the reliability of pipeline transport and its security. 